\title{
Does Screen Size Matter? An Examination of the Effectiveness of Mobile Banner Ads on Smartphones vs. Phablets (An Abstract)
}

\author{
Ying Jiang
}

\begin{abstract}
With the recent dramatic increase in the smartphone ownership and usage, the spending on mobile advertising surpassed the spending on desktop digital advertising for the first time in 2015. The current research investigates the effectiveness of these mobile banner ads. Particularly, we examine which location on a screen (top vs. bottom) is more effective for mobile banner ads displayed on smartphones vs. phablets. Results from an experiment show that the mobile banner ads are more effective in terms of attitude and consideration of set formation when displayed on the top (vs. bottom) of the screen on smartphones, but such difference is not significant for phablets.
\end{abstract}

References available upon request.

Acknowledgment This research was supported by the Social Sciences and Humanities Research Council of Canada.

\footnotetext{
Y. Jiang $(\bowtie)$

University of Ontario, Oshawa, ON, Canada

e-mail: Ying.Jiang@uoit.ca
} 